\title{
ESTUDIOS PEDAGÓGICOS NÚMERO ESPECIAL 40 AÑOS
}

\section{Editorial}

"Tenemos una profunda convicción. Es urgente ynecesario hacer investigación educacional. Así los investigadores de las diversas Universidades - a través del diálogo renovador y vivificador - podrán intercambiar conocimientos y experiencias. Así las autoridades educacionales nacionales y regionales contarán con la colaboración adecuada que les ayudará a tomar las delicadas decisiones que nuestra patria requiere”.

40 años atrás, fueron éstas las palabras con que el entonces Decano de la Facultad de Letras y Educación de una joven Universidad Austral, Doctor Erwin Haverbeck Ojeda, daba inicio a la Revista Estudios Pedagógicos (EPED). Su convicción explicitaba un llamado, la fuerza de una interpelación, hacia la conducción de investigaciones realistas y comprometidas que promovieran un diálogo vinculante con las decisiones político-educativas de la época.

El nombre dado a la revista encerraba además principios relevantes. Tomando distancia de reduccionismos, éste se rebelaba contra enfoques técnicos e instrumentales que pretendían, y aun pretenden hoy, concebir la educación como un campo de aplicación de teorías y a la Pedagogía como práctica de modelación de conductas. Se trataba, por cierto, de un enfoque tradicional con base en los aportes de Tyler, autor fuertemente cuestionado por el movimiento de la nueva sociología de la educación.

EPED se orientó más bien hacia una epistemología sustentada en la articulación permanente de la teoría y la práctica educativa, un conocimiento con base en lo cotidiano, en la fuerza de una práctica compleja y comprometida. La convicción sostenida por el cuerpo editorial de aquella época fue valiente, no neutral, incluso subversiva, en virtud de las condiciones políticas y académicas existentes. Nuestro país en dictadura y la Universidad Austral bajo la tutela de un rector militar designado, ¿qué garantías, qué resguardos posibles podrían reducir la certeza de la evidente reacción ante el pensar divergente?

"Queremos dar a conocer nuestros trabajos para que no haya repetición de esfuerzos. Deseamos estimular el trabajo interdisciplinario”.

El sumario del primer $n^{\circ} 1$ reflejaba parte de tal esfuerzo: 11 artículos clasificados en tres secciones; reportes de investigación, artículos de reflexión y una reseña, que atendieron a temas tales como la repetición de educación curso en básica, el análisis de factores socioculturales en la enseñanza de idiomas, la didáctica de la expresión escrita, la globalización y la enseñanza, la organización del curriculum, la relación profesor-alumno, y una muy reveladora e ilustrativa descripción de las políticas educacionales del gobierno de Chile. 
Los 90' inauguran para EPED un escenario muy distinto al de la dictadura, aunque no menos significativo en sus impactos. El cierre de las pedagogías en la universidad y la partida de sus profesores fueron avatares que sin duda debilitaron la constitución de una masa crítica y la construcción-divulgación de conocimiento científico educacional a nivel regional y nacional. Esto, sin embargo, no mermó el espíritu de aquellos que aun permanecían, quienes lograron mantener con vida la revista a través de la publicación de un número anual.

A 40 años del primer número, y en el contexto de una sostenida revitalización del área de pedagogía y educación iniciada por las autoridades de la Facultad de Filosofía y Humanidades y del nuevo Instituto de Ciencias de la Educación, nuestra revista ha cobrado renovadas fuerzas permitiéndole ocupar hoy un destacado lugar a nivel nacional e internacional entre las revistas del área como en las preferencias y el reconocimiento que nos brindan los investigadores.

Con todo, el nuevo escenario no ha estado ajeno a desafíos. La necesidad de impulsar y divulgar miradas trans-disciplinares y perspectivas complejas sobre la educación se contraponen paradójicamente con aquello que autores como Ball ${ }^{1}$ han advertido como una marcada tendencia a la privatización y naturalización del conocimiento científico educativo en manos de agencias de indexación y clasificación más interesadas en el control del mercado de las publicaciones que en la rigurosidad, pertinencia y relevancia de sus contribuciones.

Como cuerpo editorial, y ante la fuerte demanda de los investigadores por publicar en EPED, la estrategia asumida ha sido la de ampliar el número de artículos publicables y mejorar su proceso de gestión, sosteniendo permanentemente los principios de su fundación.

Es por esta razón que en el presente número hemos querido extender un abrazo a nuestra historia, a nuestros colegas directores y editores, contribuyentes y evaluadores, con el objetivo de afianzar nuestra memoria y de reivindicar nuestra identidad a través de la reedición de aquellos artículos que dieron cuerpo al primer ejemplar de la revista un segundo semestre del año 1976, particularmente bajo el desarrollo de una perspectiva críticocreativa, de convergencia y permanencia que sostienen los académicos y académicas que hoy integramos el área de educación y pedagogía de la Facultad de Filosofía y Humanidades de la Universidad Austral de Chile.

\section{Alberto Galaz \\ Director \\ Marta Silva \\ Editora}

Revista Estudios Pedagógicos

Instituto de Ciencias de la Educación

Facultad de Filosofía y Humanidades

Ball, S. (2009). Globalización, mercantilización y privatización: tendencias internacionales en educación y política educativa. Revista de Política Educativa, № 1. págs. 17-35 